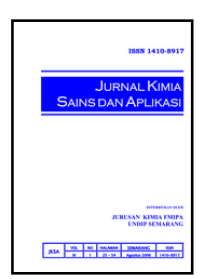

\title{
Telaah Surfaktan untuk Proses Enhanced Oil Recovery (EOR) dan Profil Adsorpsi Surfaktan A-Olefin Sulfonates (AOS)
}

\author{
Rohayati Juita ${ }^{\mathrm{a}}$, Arnelli $^{\mathrm{a}}{ }^{*}$, Yusniati $^{\mathrm{a}}$ \\ a Physical Chemistry Laboratory, Chemistry Department, Faculty of Sciences and Mathematics, Diponegoro University, Jalan Prof. \\ Soedarto, Tembalang, Semarang \\ * Corresponding author: arnelli@live.undip.ac.id
}

\section{Article Info}

Keywords: enhanced oil recovery (EOR), $a$ Olefin Sulfonates (AOS), sandstone, limestone
Kata Kunci: enhanced oil recovery (EOR), aOlefin Sulfonates (AOS), sandstone, limestone

\section{Abstract}

A surfactant study for enhanced oil recovery (EOR) and surfactant adsorption profile aOlefin Sulfonates (AOS) was performed. This study aims to determine the type of surfactant that can be used for the enhanced oil recovery (EOR) process and to know the surfactant adsorption profile. This research was divided into 2 stages, the first step was the screening of surfactant, the second stage was the adsorption of surfactant in sandstone and limestone rock. Screening of surfactants performed included a dilution test in which the surfactant is dissolved in aquadest. The compatibility test in which the surfactant was dissolved in water and its formation was observed for 3 days. Thermal stability test in which surfactants that pass compatibility were heated to $80^{\circ} \mathrm{C}$ for 8 weeks. Adsorption of surfactants was carried out in sandstone (silica sandstone) sand, bangka sand, poor sand and limestone. The rocks were immersed for 168 hours in a $0.6 \%$ surfactant solution of S24 (a-Olefin Sulfonates); $1.2 \% ; 1.8 \%$, filtered and then centrifuged and measured their absorbance by UV-Vis spectroscopy. AOS surfactant $0.6 \%$ in silica sand and $1.0 \%$ surfactant AOS in unadsorbed poor sand, making it suitable for enhanced oil recovery (EOR) process.

\section{Abstrak}

Telaah surfaktan untuk proses enhanced oil recovery (EOR) dan profil adsorpsi surfaktan a-Olefin Sulfonates (AOS) telah dilakukan. Penelitian ini bertujuan untuk mengetahui jenis surfaktan yang dapat digunakan untuk proses enhanced oil recovery (EOR) dan mengetahui profil adsorpsi surfaktan. Penelitian ini terbagi 2 tahap, yaitu tahap pertama adalah screening surfaktan, tahap kedua adalah adsorpsi surfaktan dalam batuan sandstone dan limestone. Screening surfaktan yang dilakukan, meliputi: uji pelarutan di mana surfaktan dilarutkan dalam akuades. Uji compatibility di mana surfaktan dilarutkan dalam air dan formasinya diamati selama 3 hari. Uji thermal stability di mana surfaktan yang lolos compatibility dipanaskan $80^{\circ} \mathrm{C}$ selama 8 minggu. Adsorpsi surfaktan dilakukan di dalam batuan sandstone (batu pasir silika), pasir bangka, pasir malang dan limestone (batu kapur). Batuan direndam selama 168 jam dalam larutan surfaktan S24 (a-Olefin Sulfonates) 0,6\%; 1,2\%; 1,8\%, disaring kemudian disentrifuge dan diukur absorbansinya dengan spektroskopi UV-Vis. Surfaktan AOS 0,6\% dalam batu pasir silika dan surfaktan AOS $1,8 \%$ dalam pasir malang tidak teradsorpsi, sehingga cocok untuk proses enhanced oil recovery (EOR).

\section{Pendahuluan}

Eksplorasi minyak bumi dapat berupa eksplorasi ladang minyak baru dan recovery (pengambilan) secara optimal pada ladang minyak tua. Faktor utama penyebab penurunan produksi minyak bumi di Indonesia adalah sumur-sumur minyak di Indonesia 
merupakan ladang minyak tua dan belum ditemukannya ladang minyak baru. Menurut Curbelo dkk. [1], injeksi bahan kimia dapat meningkatkan energi dorong pada reservoir (ladang minyak) melalui pendesakan minyak di antara batuan sehingga membentuk kondisi yang baik untuk memaksimumkan recovery minyak, proses tersebut dikenal dengan proses enhanced oil recovery (EOR).

Minyak dapat diproduksi $5-30 \%$ dari original oil in place (OOIP). Metode EOR mampu mengoptimalkan pengurasan ladang minyak tua dimana mampu memproduksikan minyak sampai 70\% dari OOIP [1], sedangkan tahap konvensional (fase primer dan fase sekunder) hanya mampu memproduksi minyak sebesar 20-40\%. Indonesia telah menerapkan fase sekunder berupa teknologi injeksi air (waterflooding). Teknologi tersebut menghasilkan kinerja produksi yang buruk karena memiliki water cut yang tinggi sebesar 95-99\%. Dalam memperbaiki kinerja produksi minyak bumi maka dilakukan tahap lanjut (fase tersier) berupa EOR. Salah satu metode EOR, yang dilakukan adalah chemical flooding. Chemical flooding dapat dilakukan dengan menggunakan surfaktan [2].

Surfaktan (surface active agent) merupakan senyawa aktif yang mempunyai struktur amphifilik, yang terdiri dari gugus hidrofilik dan lipofilik [3, 4] yang dapat menurunkan tegangan permukaan antara dua fase yang berbeda, yaitu minyak dan air [3], sehingga dapat dimanfaatkan dalam proses EOR. Gaya adhesi dari surfaktan (gugus-R ) dengan minyak akan mengurangi gaya kohesi antara $\mathrm{RSO}_{3}{ }^{-}$dari surfaktan sehingga menyebabkan penurunan tegangan permukaan antara minyak dengan air, yang mengakibatkan minyak terbebas dari core (batuan) [5].

Muherei $d k k$. [6], mengadsorpsi surfaktan SDS (anionik) dan TX-100 (nonionik) dalam serpih dan batuan sandstone dengan waktu adsorpsi 3 jam dan 16 jam, disentrifuge $100 \mathrm{rpm}$. Pada tahun 2011, Chen melakukan penelitian adsorpsi surfaktan, TX-100 (nonionik), Brij35 (nonionik) dan SDBS (anionik) dalam 4 tanah, dengan waktu adsorpsi 12 jam dan 24 jam, disentrifuge $3800 \mathrm{rpm}$. Bera $d k k$. [7] melakukan penelitian adsorpsi surfaktan SDS (anionik) dan CTAB (kationik) dalam pasir dengan waktu adsorpsi 24 jam, disentrifuge $120 \mathrm{rpm}$.

Penelitian adsorpsi surfaktan AOS (anionik) dalam batuan sandstone (batu pasir silika, pasir malang dan pasir bangka) dan limestone (batu kapur) dengan waktu adsorpsi 168 jam dan sentrifuge $600 \mathrm{rpm}$ belum pernah dilakukan. Pemilihan batuan sandstone dan limestone sebagai simulasi untuk proses EOR, karena keberadaan minyak banyak terdapat pada batuan sedimentasi yang terdiri dari sandtone dan limestone.

Pemilihan surfaktan merupakan proses yang penting dalam mempengaruhi keberhasilan EOR, sehingga dibutuhkan penelitian laboratorium yang intensif untuk mendapatkan surfaktan yang cocok pada reservoir. Surfaktan yang digunakan untuk EOR harus lolos terlebih dahulu pada uji screening surfaktan, seperti pelarutan dalam aquades, uji compatibilty, uji thermal stability sebelum dilanjutkan proses adsorpsi. Surfaktan yang kurang teradsorpsi yang dapat diaplikasikan dalam enhanced oil recovery (EOR). Surfaktan yang teradsorpsi tinggi menyebabkan, surfaktan akan berikatan dengan batuan dan surfaktan terjebak dalam batuan, sehingga minyak tidak bisa keluar dari batuan.

\section{Metode Penelitian}

\section{Alat dan Bahan}

Alat yang digunakan adalah alat gelas standar penelitian, neraca analitik, micropipete, kertas whatman, oven, kertas $\mathrm{pH}$, alat penangas, 1 set alat sentrifuge, spektrofotometer UV-Vis Perklin Elmer, autosorb 6B Quantachrome. Bahan meliputi Surfaktan: So, S8, S9, S10, S11, S12, S14, S15, S16, S17, S18, S19, S20, S22, S23. Sufaktan anionik: S13 (Sodium Lauril Sulfat), S24 (Alfa Olefin Sulfonat), S25 (Secondary alkane sulfonat), S26 (Sodium Lauril Eter Sulfat). Surfaktan nonionik: S27 (PolyEthylene Oxide/Propylene Oxide), S28 (PolyEthylene Oxide/Propylene Oxide), S29 (Block Copolymer Surfactant Nonionic), S30 (PolyEthylene Oxide/Propylene Oxide), S31 (Block Copolymer Surfactant Nonionic), S32 (Block Copolymer Surfactant Nonionic), S33 (Block Copolymer Surfactant Nonionic), S34 (PolyEthylene Oxide/Propylene Oxide), S35 (PolyEthylene Oxide/Propylene Oxide), S36 (PolyEthylene Oxide/Propylene Oxide), S37 (PolyEthylene Oxide/Propylene Oxide), S38 (Block Copolymer Surfactant Nonionic), S39 (Nonionic tri block copolymer), S40A (PolyEthylene Oxide/Propylene Oxide), S40B (PolyEthylene Oxide/Propylene Oxide), SF01, SF02, air formasi, akuades, sandstone dan limestone

\section{Pelarutan Surfaktan dengan Aquades}

Diambil 1,5 mL surfaktan dilarutkan dalam 3,5 mL aquades. Sampel yang sukar larut, maka dilakukan dengan pemanasan. Surfaktan yang lolos pada tahap pelarutan dengan akuades, yaitu: dapat larut sempurna dan berwarna jernih.

\section{Uji Compatibility}

Diambil 0,6 mL surfaktan dilarutkan dalam 9,4 mL air formasi, kemudian dikocok hingga homogen, lalu didiamkan selama 3 hari dan diamati. Surfaktan yang lolos uji compatibility, yaitu larutan yang tetap bening dan tidak terbentuk endapan.

\section{Uji Thermal Stability}

Sampel yang lolos uji compatibility disiapkan, kemudian sampel dipanaskan pada suhu $80^{\circ} \mathrm{C}$ dan diamati selama 8 minggu. Sampel yang lolos thermal stability, yaitu larutan yang tetap bening dan tidak terbentuk endapan dan minyak.

\section{Penentuan Kurva Standar Surfaktan}

Surfaktan dilarutkan dalam air formasi dibuat berbagai konsentrasi, ditentukan panjang gelombang maksimum dengan spektrofotometer UV-Vis, kemudian diukur absorbansi yang dapat dibuat kurva standar surfakan. 
Adsorpsi surfaktan dalam batuan sandstone dan limestone

Surfaktan dalam air formasi di campurkan dalam batuan sandstone dan limestone sebanyak $50 \mathrm{~g}$, didiamkan selama 168 jam, kemudian dilakukan penyaringan, disentrifuge $600 \mathrm{rpm} 10$ menit, kemudian diukur absorbansinya dengan menggunakan spektrofotometer UV-Vis dengan panjang gelombang maksimum.

Pengukuran luas area permukaan dan ukuran pori batuan dengan Autosorb 6B Quantachrome

Sebelum dilakukan analisis, dilakukan treatment batuan sandstone (batu pasir silika, pasir bangka, dan pasir malang) dan limestone (batu kapur) yang sudah dihaluskan terlebih dahulu yang disebut degassing. Proses degassing, mula-mula batuan dipanaskan pada suhu $300{ }^{\circ} \mathrm{C}$ selama 5 jam, sambil dilakukan pemvakuman, kemudian dialirkan gas nitrogen dan dilakukan analisis ukuran pori batuan dengan autosorb.

\section{Hasil dan Pembahasan}

\section{Uji Pelarutan dengan Akuades}

Uji pelarutan surfaktan bertujuan agar dapat diketahui kelarutan surfaktan dalam aquades. Surfaktan $(1,5 \mathrm{~mL})$ dilarutkan dalam aquades $(3,5 \mathrm{~mL})$. Terdapat 39 sampel yang dilarutkan dalam aquades. Sampel yang larut sempurna, jernih (clear solution), tidak keruh (hazy solution) dan tidak membentuk endapan maka dapat dilakukan uji selanjutnya yakni uji compatibility.

Sampel yang lolos pada tahap pelarutan dengan akuades sejumLah 29 buah, yakni surfaktan So, S8, S9, S10, S11, S12, S13, S14, S15, S16, S17, S18, S20, S21, S22, S24, S25, S26, S27, S28, S30, S31, S32, S33, S35, S36, S40A, SF01, SF02. Surfaktan dapat larut sempurna, karena adanya prinsip like dissolve like, dimana surfaktan yang mempunyai rantai hidrofob yang lebih panjang, maka kelarutan dalam akuades berkurang.

Surfaktan S13, yaitu surfaktan sodium lauril sulfat (SLS) dengan rumus molekul $\mathrm{C}_{12} \mathrm{H}_{25} \mathrm{SO}_{4} \mathrm{Na}$ mempunyai sifat yang larut dalam air, sehingga pada pengamatan. S13 larut dalam air. Surfaktan S24, yaitu surfaktan aOlefin Sulfonates (AOS) dengan rumus molekul $\mathrm{RCH}=\mathrm{CH}\left(\mathrm{CH}_{2}\right) \mathrm{nSO}_{3} \mathrm{Na} \quad \mathrm{n}=14-16, \quad$ campuran alkenesulfonates dan hydroxyalkanesulfonate mempunyai sifat kelarutan dengan air yang sangat tinggi, oleh karena itu surfaktan S24 dapat larut dengan air.

Surfaktan S25, yaitu surfaktan Paraffin Sulfonates/Secondary n-Alkanesulfonates (SAS), dimana n-parafinnya atom karbon $\mathrm{C}(14-17)$ dengan $\mathrm{SO}_{2}$ dan $\mathrm{O}_{2}$, dalam hal ini surfaktan SAS mempunyai sifat kelarutan dalam air yang baik, sehingga surfaktan S25 dapat larut dengan sempurna dengan air. Surfaktan Polyethylene Oxide (PEO), yaitu surfaktan S27, S28, S30, S35, S36 dan S40a mempunyai sifat yang dapat larut dalam air, sehingga dalam pengamatan surfaktan tersebut larut dalam air. Surfaktan yang tidak larut sempurna, berwarna keruh dan membentuk endapan, maka surfaktan tersebut dibuang.

\section{Uji Compatibility}

Uji compatibility ini bertujuan untuk mengetahui kelarutan surfaktan terhadap air formasi. Larutan yang memenuhi uji compatibility adalah larut sempurna, jernih (clear solution), tidak keruh (hazy solution) dan tidak membentuk endapan.

Salah satu pertimbangan penting dalam pemilihan surfaktan dalam aplikasi EOR adalah kompatibilitas surfaktan dengan air formasi yang sesuai dalam reservoir tertentu. Air formasi yang diambil dari sumur minyak mengandung berbagai ion, yaitu $\mathrm{Ca}^{2+}, \mathrm{Mg}^{2+}$, $\mathrm{Fe}^{2+}, \mathrm{CO}_{3}{ }^{2-}, \mathrm{SO}_{4}{ }^{2-}$ dan $\mathrm{Cl}^{-}$.

Sampel yang telah lolos pada tahap pelarutan dalam akuades, dibuat larutan surfaktan $6 \%$ yang dilarutkan dalam air formasi. Setelah itu dilakukan pengamatan dengan waktu tertentu selama 3 hari. Larutan yang memenuhi uji compatibility adalah larut sempurna, jernih (clear solution), tidak keruh (hazy solution) dan tidak membentuk endapan.

Larutan surfaktan yang memenuhi uji compatibility ada 20 sampel yaitu surfaktan So, S8, S9, S10, S12, S13, S14, S16, S18, S20, S22, S24, S26, S27, S28, S30, S31, S32, S36, dan SF01. Larutan tersebut berada dalam 1 fasa dimana dapat menunjukkan bahwa surfaktan tersebut larut sempurna, karena surfaktan tersebut sifat kepolaranya tinggi. Surfaktan yang bersifat lebih polar merupakan surfaktan yang memiliki hidrofilik lebih kuat daripada hidrofobiknya misalnya sodium lauril sulfat (SLS).

Surfaktan S24 (a-Olefin Sulfonates) mempunyai sifat yang dapat larut dengan air keras dan stabil pada air yang mempunyai salinitas yang tinggi, sehingga dalam pengamatan S24 dapat larut dengan air formasi. Surfaktan Polyethylene Oxide (PEO), yaitu surfaktan S27, S28, S30 dan S36 mempunyai sifat yang dapat larut dalam air keras, sehingga pada pengamatan surfaktan tersebut larut dalam air formasi, namun ada surfaktan Polyethylene Oxide (PEO), yaitu S35 dan S40a pada pengamatan larutan berwarna keruh, dimungkinkan surfaktan berinteraksi dengan air formasi.

Larutan tersebut jika diaplikasikan dalam EOR maka akan dapat membuka pori-pori batuan sehingga minyak yang terperangkap akan terangkat, sedangkan, pada larutan yang keruh, maupun membentuk lebih dari 1 fasa merupakan larutan yang lebih nonpolar dimana hidrofobik lebih kuat daripada hidrofiliknya. Surfaktan yang membentuk 2 fasa terdapatnya endapan, hal ini dikarenakan surfaktan berinteraksi dengan air formasi yang mempunyai kation dan anion didalamnya. Larutan tidak memenuhi parameter uji compatibility, larutan surfaktan tersebut adalah S11, S15, S17, S22, S25, S33, S35, S40A, dan SF02 dan larutan ini dibuang.

Surfaktan S25 adalah surfaktan secondary alkane sulfonate dengan rumus kimia $\mathrm{CH}_{3}\left(\mathrm{CH}_{2}\right) \mathrm{nCH}\left(\mathrm{SO}_{3} \mathrm{Na}\right)\left(\mathrm{CH}_{2}\right) \mathrm{mCH}_{3}(\mathrm{n}+\mathrm{m}=11-14)$ apabila bereaksi dengan air formasi $\left(\mathrm{SO}_{4}{ }^{2-}\right)$ dapat membentuk 
endapan $\mathrm{Na}_{2} \mathrm{SO}_{4}$ sehinga pada pengamatan surfaktan S25 membentuk endapan dan surfaktan secondary alkane sulfonate (SAS) mempunyai sifat tidak larut dengan air keras. formasi:

Reaksi secondary alkane sulfonate (SAS) dengan air

$$
\left[\begin{array}{l}
\mathrm{SO}_{3}{ }^{-} \\
{[\mathrm{n}+\mathrm{m}=11-14)}
\end{array}\right.
$$

\section{Uji Thermal Stability}

Uji thermal stability dilakukan untuk mengetahui kestabilan surfaktan terhadap suhu formasi. Surfaktan yang baik akan tetap stabil oleh pengaruh suhu. Uji thermal stability dilakukan 8 minggu dengan cara memanaskan 20 sampel yang lolos uji compatibility pada suhu $80^{\circ} \mathrm{C}$ dan tiap waktu tertentu dilakukan pengamatan surfaktan yang bewarna jernih dan tidak membentuk endapan. Suhu resevoir antara $70-80^{\circ} \mathrm{C}$, sehingga digunakan suhu pada thermal stability $80^{\circ} \mathrm{C}$.

Larutan yang lolos uji thermal stability dapat tetap stabil (tidak rusak oleh panas) dengan ditandai bahwa larutan tersebut tetap berada dalam 1 fasa, tetap bening dan tidak muncul endapan. Dalam waktu 24 jam, surfaktan yang memiliki 1 fasa, bening dan tidak ada endapan, yakni larutan surfaktan S8, S10, S13, S14, S20, S24, S30 dan S31. Dalam waktu 8 minggu, larutan surfaktan yang lolos uji thermal stability, yaitu S13, S14, S24, S30 dan S31. Larutan surfaktan yang lain, sudah nampak ada perubahan dengan mulai munculnya endapan atau munculnya 2 fase yang terdapat minyak.

Keberadaan endapan pada uji thermal stability menunjukkan bahwa surfaktan tersebut tidak stabil pada suhu $80^{\circ} \mathrm{C}$ dan kemungkinan struktur surfaktan sudah rusak karena adanya pemanasan tersebut. Uji thermal stability ini dapat diketahui jenis surfaktan yang stabil pada suhu reservoir untuk aplikasi EOR.

Surfaktan S24 (a-Olefin Sulfonates) mempunyai titik didih $1000 \mathrm{C}$ dan akan terdegradasi apabila melewati suhu 2870 C, oleh karena itu surfaktan S24 tetap stabil dan membentuk 1 fasa pada thermal stability. Surfaktan yang tidak lolos thermal stability dikarenakan surfaktan yang larut dalam air formasi, molekul surfaktannya terkonsentrasi dipermukaan, akibat adanya penambahan suhu, molekul surfaktan menjadi tidak terkonsentrasi dan banyak molekul di dalam fasa ruah (fasa di bawah permukaan).

\section{Adsorpsi Surfaktan a-Olefin Sulfonates (AOS) Dalam Batuan Sandstone dan Limestone}

Surfaktan yang digunakan untuk proses adsorpsi, yaitu S24. Sampel larutan surfaktan S13 S14 S30 dan S31 tidak digunakan, karena sampelnya terbatas, sehingga tidak cukup untuk di adsorpsi batuan sandstone dan limestone. Dari hasil uji thermal stability selama 8 minggu, larutan surfaktan yang lolos adalah S13, S14, S24, S30, dan S31. Surfaktan yang lolos uji thermal stability dilakukan uji adsorpsi pada batuan. Surfaktan dalam air formasi di campurkan dengan batuan sandstone (pasir silika, pasir malang dan pasir bangka) dan batuan limestone (batu kapur), waktu adsorpsi yang dilakukan selama 168 jam.

Adsorpsi surfaktan adalah menempelnya molekulmolekul surfaktan pada permukaan batuan. Dari data penelitian didapatkan hasil bahwa adsorpsi surfaktan dalam batu kapur (limestone) merupakan adsorpsi yang paling tinggi dibandingkan adsorpsi surfaktan dalam batu pasir silika, pasir malang dan pasir bangka (sandstone), pasir bangka paling mengadsorpsi dibandingkan pasir malang dan pasir silika. Surfaktan yang baik untuk digunakan dalam enhanced oil recovery (EOR), yaitu surfaktan yang kurang teradsorpsi, karena apabila surfaktan tersebut memiliki tingkat adsorpsi yang tinggi maka surfaktan akan menempel didalam batuan dan tidak dapat menarik minyak untuk keluar dari batuan.

\begin{tabular}{|c|c|c|}
\hline Batuan + Surfaktan & $\begin{array}{l}\text { Konsentrasi } \\
\text { sisa }(\%)\end{array}$ & $\begin{array}{l}\text { Teradsorpsi } \\
(\%)\end{array}$ \\
\hline $\begin{array}{c}\text { Batu kapur + S24 } \\
0,6 \%\end{array}$ & 0 & 100 \\
\hline $\begin{array}{c}\text { Batu kapur }+ \text { S24 } \\
1,2 \%\end{array}$ & 0,14 & 88,33 \\
\hline $\begin{array}{c}\text { Batu kapur + S24 } \\
1.8 \%\end{array}$ & 0,46 & 74,44 \\
\hline $\begin{array}{c}\text { Pasir silika + S24 } \\
0,6 \%\end{array}$ & 0,3 & 50 \\
\hline $\begin{array}{c}\text { Pasir silika + S24 } \\
1,2 \%\end{array}$ & 1,16 & 3,33 \\
\hline $\begin{array}{c}\text { Pasir silika + S24 } \\
1.8 \%\end{array}$ & 1,8 & 0 \\
\hline $\begin{array}{c}\text { Pasir malang }+\mathrm{S} 24 \\
0,6 \%\end{array}$ & 0,6 & 0 \\
\hline $\begin{array}{c}\text { Pasir malang } \\
1,2 \%\end{array}$ & 1,16 & 3,33 \\
\hline $\begin{array}{c}\text { Pasir malang + S24 } \\
1.8 \%\end{array}$ & 1,6 & 11,11 \\
\hline $\begin{array}{c}\text { Pasir bangka }+\mathrm{S} 24 \\
0,6 \%\end{array}$ & 0 & 100 \\
\hline $\begin{array}{c}\text { Pasir bangka }+\mathrm{S} 24 \\
1,2 \%\end{array}$ & 0,74 & 38,33 \\
\hline $\begin{array}{c}\text { Pasir bangka }+\mathrm{S} 24 \\
1.8 \%\end{array}$ & 0,86 & 52,22 \\
\hline
\end{tabular}

Tabel 1: Hasil Adsorpsi Surfaktan S24 (Alfa Olefin Sulfonat)

Mekanisme surfaktan dengan batuan dalam pengambilan minyak, yaitu gaya tolak-menolak antara kepala surfaktan anionik yang bermuatan negatif $\left(\mathrm{SO}_{3}{ }^{-}\right)$ dengan batuan sandstone $\left(\mathrm{SiO}_{2}\right)$ yang memiliki banyak parsial negatif, surfaktan yang mengikat minyak pada bagian gugus $\mathrm{R}$ akan bergerak menjauh dari batuan dan ini akan mengakibatkan menurunkan oil wet dan menaikkan water wet [8]. Kondisi ini akan menyebabkan turunnya gaya adhesi antara minyak dan batuan sehingga ak akan lepas dan lebih mudah mengalir dan 
sifat batuan akan berubah di water wet. Sebaliknya pada batuan limestone yang bermuatan positif $\left(\mathrm{Ca}^{2+}, \mathrm{Mg}^{2+}\right)$, karena adanya gugus karbonat, sehingga menyebabkan gaya tarik-menarik dan menaikkan gaya adhesi sehingga sifat batuan akan berubah menjadi oil wet [9].

Analisa Pori Batuan dengan Autosorb (UOP-425; ASTM D-3663; D-4222; D-4641)

Analisis pori dilakukan untuk mengetahui surface area (luas permukaan), pore volume (volume pori), dan pore diameter (ukuran pori). Prinsip analisis ini didasarkan atas adsorpsi fisis gas nitrogen pada permukaan dan pori batuan. SejumLah volume gas nitrogen yang dimasukkan dalam sistem (sampel) akan memberikan perubahan tekanan dan diukur sebagai tekanan relatif. Tekanan relatif tersebut akan sebanding dengan volume gas yang diinjeksikan. Dari grafik tekanan relatif terhadap volume gas teradsorpsi, density gas, berat molekul gas, maka akan didapatkan surface area.

Dari tabel 2 didapatkan hasil bahwa luas permukaan 2 batu pasir silika, pasir malang dan pasir bangka (sandstone), yaitu $0,226 \mathrm{~m}^{2} / \mathrm{g} ; 0,737 \mathrm{~m}^{2} / \mathrm{g} ; 0,443 \mathrm{~m}^{2} / \mathrm{g}$ lebih kecil dibandingkan dengan batu kapur (limestone), yaitu $3,664 \mathrm{~m}^{2} / \mathrm{g}$. Surfaktan anionik dalam batu kapur (limestone), lebih teradsorpsi dengan surfaktan anionik dalam batu pasir (sandstone). Batu pasir silika memiliki luas permukaan lebih kecil dibandingkan batu pasir malang dan batu pasir bangka, sehingga kurang mengadsorpsi surfaktan, terbukti dengan kurangnya kemampuan mengadsorpsi surfaktan S24. Batu pasir malang luas permukaanya lebih besar dibandingkan pasir silika dan bangka, namun kurang dalam mengadsorpsi surfaktan S24. Hal ini yang lebih cocok digunakan dalam proses enhanced oil recovery (EOR), yaitu batu pasir malang dan pasir silika.

Tabel 2: Hasil analisa pori batuan

\begin{tabular}{ccccc}
\hline & \multicolumn{4}{c}{ Sampel Batuan } \\
\cline { 2 - 5 } Pengamatan & $\begin{array}{c}\text { Batu } \\
\text { Pasir } \\
\text { Silika }\end{array}$ & $\begin{array}{c}\text { Batu } \\
\text { Pasir } \\
\text { Malang }\end{array}$ & $\begin{array}{c}\text { Batu } \\
\text { Pasir } \\
\text { Bangka }\end{array}$ & $\begin{array}{c}\text { Batu } \\
\text { Kapur }\end{array}$ \\
\hline $\begin{array}{c}\text { Surface Area } \\
\text { BET (m²/g) } \\
\text { Total Pore } \\
\text { Volume } \\
\text { (cc/g) } \\
\begin{array}{c}\text { Average } \\
\text { Pore Radius } \\
\AA\end{array}\end{array}$ & 0,226 & 0,737 & 0,443 & 3,664 \\
\hline & 978,34 & 133,05 & 306,93 & 98,863 \\
\hline
\end{tabular}

\section{Kesimpulan}

Surfaktan yang lolos uji pelarutan dengan aquades adalah surfaktan So, S8, S9, S10, S11, S12, S13, S24, S15, S16, S17, S18, S20, S21, S22, S24, S25, S26, S27, S28, S30, S31, S32 S33, S35, S36, S40A, SF01 dan SF02. Surfaktan yang lolos uji compatibility adalah surfaktan So, S8, S9, S10,S11, S12, S13, S24, S16, S18, S20, S21, S24, S27, S28, S30, S31, S36, S40A, SF01. Surfaktan yang lolos uji thermal stability adalah surfaktan S13 (Sodium Lauril Sulfat), S14, S24 (Alfa Olefin Sulfonat), S30 (PolyEthylene
Oxide/Propylene Oxide), dan S31 (Block Copolymer Surfactant Nonionic) dan Kemampuan adsorpsi surfaktan S24 dalam limestone lebih besar dibandingkan dengan sandstone (batu pasir silika, pasir malang dan pasir bangka). Adsorben batu pasir malang dengan adsorbat surfaktan S24 0,6\% dan adsorben batu pasir silika dengan adsorbat surfaktan S24 $1,8 \%$ yang baik digunakan untuk aplikasi enhanced oil recovery (EOR).

\section{Daftar Pustaka}

[1] Fabíola D. S. Curbelo, Vanessa C. Santanna, Eduardo L. Barros Neto, Tarcílio Viana Dutra, Tereza N. Castro Dantas, Afonso A. Dantas Neto, Alfredo I. C. Garnica, Adsorption of nonionic surfactants in sandstones, Colloids and Surfaces A: Physicochemical and Engineering Aspects, 293, 1, (2007) 1-4 http://dx.doi.org/10.1016/j.colsurfa.2006.06.038

[2] Tahmineh Amirianshoja, Radzuan Junin, Ahmad Kamal Idris, Omeid Rahmani, A comparative study of surfactant adsorption by clay minerals, Journal of Petroleum Science and Engineering, 101, (2013) 21-27 http://dx.doi.org/10.1016/j.petrol.2012.10.002

[3] Mohammad Ali Ahmadi, Yaser Arabsahebi, Seyed Reza Shadizadeh, Sara Shokrollahzadeh Behbahani, Preliminary evaluation of mulberry leaf-derived surfactant on interfacial tension in an oil-aqueous system: EOR application, Fuel, 117, (2014) 749-755 http://dx.doi.org/10.1016/j.fuel.2013.08.081

[4] Irine Ayu Febiyanti, Ahmad Suseno, Priyono Priyono, Pengaruh Konsentrasi Surfaktan CTAB (Cetyltrimethylammonium bromide) pada Modifikasi Lempung dengan Oksida Besi sebagai Pemilar, Jurnal Kimia Sains dan Aplikasi, 16, 3, (2013) 79-83

[5] Santanu Paria, Kartic C. Khilar, A review on experimental studies of surfactant adsorption at the hydrophilic solid-water interface, Advances in Colloid and Interface Science, 110, 3, (2004) 75-95 http://dx.doi.org/10.1016/j.cis.2004.03.001

[6] Mazen A. Muherei, Radzuan Junin, Amer B. Bin Merdhah, Adsorption of sodium dodecyl sulfate, Triton X100 and their mixtures to shale and sandstone: A comparative study, Journal of Petroleum Science and Engineering, 67, 3, (2009) 149-154 http://dx.doi.org/10.1016/j.petrol.2009.05.006

[7] Achinta Bera, T. Kumar, Keka Ojha, Ajay Mandal, Adsorption of surfactants on sand surface in enhanced oil recovery: Isotherms, kinetics and thermodynamic studies, Applied Surface Science, 284, (2013) http://dx.doi.org/10.1016/j.apsusc.2013.07.029

[8] R Ashayer, CA Grattoni, PF Luckham, Wettability changes during surfactant flooding, 6th International Symposium on Evaluation of Reservoir Wettability and Its Effect on Oil Recovery, Socorro, New Mexico, USA, (2000).

[9] Thomas O Allen, Alan P Roberts, Production operations: well completions, workover, and stimulation. Volume 1, (1978) 